\title{
A ressignificação da figura do especulador-investidor e as práticas de educação financeira
}

\author{
The speculator-investor figure resignification and \\ the financial education practices
}

Elaine da Silveira Leite*

\begin{abstract}
Resumo: Este artigo apresenta uma leitura de autores da socioeconomia que explicam como práticas econômicas condenadas em certas épocas foram ressignificadas e ganharam legitimidade social. Partindo da figura do especulador ganancioso, chegase à atual imagem do investidor "racional", que proclama as benesses do mundo das finanças e fortalece os programas e projetos de educação financeira. Deste modo, buscamos fornecer subsídios para elucidar o campo de formação de investidores e da educação financeira, que se constitui como um trunfo social compartilhado pelos diversos agentes e grupos produtores do mundo das finanças no Brasil.
\end{abstract}

Palavras-chave: Finanças. Investidor. Educação financeira.

\begin{abstract}
This article reviews socioeconomic literature that explains how economic practices condemned at certain times were ressignified and gained social legitimacy. It traces a history from the figure of the greedy speculator to the current image of the "rational" investor, who strengthens current financial education projects. Finally, the paper also provides subsidies to elucidate the rise of popular investors and the expansion of financial education programs in Brazil, which is constituted as a social arrangement shared by agents and producers of the country's financial world.
\end{abstract}

Keywords: Finance. Investor. Financial education.

\footnotetext{
* Doutora em Sociologia pela Universidade Federal de São Carlos (UFSCar, São Carlos, SP, Brasil), professora adjunta do departamento de Sociologia e Política e do PPG em Sociologia da Universidade Federal de Pelotas (UFPel) em Pelotas, RS, Brasil<elaineleite10@gmail.com>.
}

Civitas, Porto Alegre, v. 17, n. 1, p. 114-130, jan.-abr. 2017 


\section{A constituição da figura do investidor e a educação financeira}

O objetivo deste artigo é refletir sobre como práticas econômicas condenadas em certas épocas foram ressignificadas e ganharam legitimidade social. Para isso, partiremos da atividade do mercado financeiro, mais especificamente, ligada à bolsa de valores. Esta, por sua vez, vem associada à ideia de riqueza instantânea e de escândalos, e é alimentada pela figura do especulador, atraído pela ganância e pelo risco. A imagem das bolsas é configurada por valores que vão além da sua função puramente econômica (Le Goff, 1924; Müller, 1997).

Historicamente, algumas religiões se posicionaram contra aqueles que visavam principalmente o lucro. Toda a atividade que envolvia a usura, isto é, o ganho que não fosse resultado do trabalho produtivo, era condenado, já que os sujeitos, em tese, se preocupavam mais com o dinheiro do que com sua própria família e religião. O usurário era condenado pela Igreja, porque ele não ganhava a vida com o seu próprio suor, e, sim, pelo transcorrer do tempo, elemento que pertence a Deus. Segundo Le Goff (1924, p. 83), “Ao usurário diziam a Igreja e os poderes leigos: Escolha: a bolsa ou a vida. Mas o usurário pensava: o que eu quero é a bolsa e a vida".

Essa analogia entre a figura do especulador e a imagem de homem ganancioso até hoje pode ser observada, basta recuperarmos as notícias veiculadas pela mídia referentes aos megaespeculadores, como George Soros e Naji Nahas (Grün, 2004), os quais, muitas vezes, são vistos como capitalistas agressivos, que não trabalham para viver, que vivem da especulação. ${ }^{1}$

Vários estudos revelam como os elementos do imaginário sobre o mercado financeiro - mais especificamente sobre a bolsa de valores, seus personagens e suas ações - são construções sociais que foram elaboradas em diferentes momentos e que estão relacionadas a distintos eventos da história do capitalismo, os apresentando, ora como importantes protagonistas, ora como vilões e causadores de escândalos e das principais crises econômicas.

A especulação financeira, conforme Zaloom (2006), teve início na Europa medieval, onde os carnavais que precediam a Quaresma e outros eventos culturais faziam parte dos raros espaços sociais em que a atividade econômica com fins lucrativos era liberada pelas autoridades. Nessas ocasiões, ações de empresas comerciais podiam ser vendidas juntamente com títulos municipais e bilhetes de loteria, o que contribuiu, em um primeiro momento,

\footnotetext{
${ }^{1}$ O movimento Occupy Wall Street tem como um de seus objetivos protestar contra os homens mais ricos do mundo, entre eles, investidores de Wall Street, como George Soros.
} 
para fortalecer a analogia entre especulador e jogador. Esses eventos se caracterizavam pela forte participação popular e pelo domínio da crença na possibilidade de conquista da liberdade que adviria do sucesso financeiro (Chancellor apud Preda, 2006).

Uma das referências recorrentes, no que tange à noção de especulação, é o caso do boom do mercado das tulipas, em Amsterdã, no século 17. As tulipas trazidas do Oriente viraram "mania" entre os holandeses, e tamanha valorização levou os produtores a fecharem contratos futuros de compra e venda dessas plantas. Assim, a cada ano, o preço da tulipa inflacionava e alcançava valores elevadíssimos. Após alguns anos, porém, a "bolha das tulipas" estourou, e a maioria dos investidores perdeu muito dinheiro. Entre investidores e profissionais do mercado financeiro atual, esse caso sempre é usado como referência para definir e exemplificar os abusos e limites da especulação (Zaloom, 2006). Esse episódio também é sempre lembrado por economistas e jornalistas para ilustrar as causas e os efeitos das crises financeiras (cf. Moraes, 2008).

Segundo Cardoso (2002), dados históricos revelam que, na mesma época do "boom das tulipas", por volta da segunda metade do século 17, Joseph de la Vega em Amsterdã escreveu a primeira peça de ficção a respeito da bolsa de valores. A obra, intitulado "Confusion de confusiones", tinha o formato de um manual de finanças e nos mostra que fantasias e sátiras associadas à bolsa de valores e seus figurantes estavam presentes desde o surgimento desta instituição. $^{2}$

Na Europa, o século 18 foi marcado pelo forte entusiasmo pela atividade especulativa, o que ocasionou períodos de grande euforia, produtores de bolhas, e, na sequência, momentos de calmaria econômica. Foi neste período, aliás, que se introduziu e legitimou o conceito de "bolhas" (Kremp, 2008). Ao traçar a evolução dos fatores determinantes do comportamento do mercado de ações, Kremp enfatiza que, historicamente, ciclos que envolviam as bolhas e seus subsequentes colapsos foram os responsáveis por alterar a percepção dos agentes que participam do mercado de ações. Em 1867, com o avanço da tecnologia da comunicação, principalmente com o surgimento do ticker, uma espécie de teleimpressor de cotações da bolsa, o mercado financeiro criou uma dinâmica ainda mais sedutora, pois o referido instrumento possibilitou que a informação e o capital caminhassem "de mãos dadas" entre os mercados

\footnotetext{
${ }^{2}$ As fantasias e sátiras sobre a bolsa de valores continuam sendo produzidas nos dias atuais. É interessante notar como tal questão alimenta o mercado de filmes hollywoodianos. Cabe citar o recente e polêmico "O Lobo de Wall Street" (2013), estrelado por Leonardo DiCaprio e dirigido por Martin Scorsese.
} 
mundiais, atraindo novos investidores e dando ares de racionalidade ao mercado (Kremp, 2008; Preda, 2002; Hochfelder, 2006).

O teleimpressor tornou visível o fluxo dos preços nas tiras de papel, da mesma forma que a tela do computador dá visibilidade ao ritmo das negociações nos dias de hoje, e altera toda a dinâmica do mercado, modificando as práticas de investimento e o papel dos profissionais (Zaloom, 2006). Dito de outro modo, a introdução de novas tecnologias no mercado modificou o formato das ações e operações. Tal fenômeno é estudado atualmente por autores que analisam a performatividade dos mercados (Mackenzie e Millo, 2003; Callon, 2005).

A questão da visibilidade da dinâmica do mercado também foi sempre associada à ideia de participação. No imaginário social, o avanço da tecnologia e dos métodos de análise e o fato dos indivíduos poderem observar "ao vivo" o desenrolar do que acontece no mercado (Zaloom, 2006) reforça a ideia de que o mercado é global e aberto a todos os cidadãos. Historicamente, tal ideário teve início com a formação dos bucket shops (Preda, 2002), ${ }^{3}$ vistos como uma consequência direta da existência do ticker, que fez da especulação uma atividade popular. A transmissão direta das cotações de ações e de commodities para milhares de pessoas abriu espaço para que qualquer cidadão entrasse em um bucket shop e especulasse com ações ou commodities (Hochfelder, 2006, p. 2).

A partir do final do século 19, com a implantação do ticker e com o avanço do fluxo de informação em nível mundial, o especulador passou a figurar como um agente racional, deixando de ser visto como um jogador passional para se tornar um investidor, na medida em que ele passou a basear suas apostas em dados considerados objetivos e científicos, o que foi propiciado pelo progresso dos métodos de análise do comportamento dos mercados, que começaram a surgir naquele momento. Assim, tais fatos apontam para a construção social da figura do investidor em oposição a do especulador (Preda, 2006). ${ }^{4}$

$\mathrm{O}$ avanço do uso de dados científicos e de tabulações estatísticas fez com que o investimento no mercado financeiro passasse a ser aceito como uma atividade econômica legítima: "Financial study and scientific endeavor became a way for speculators to assert their productiveness and intelligence in the face of growing opposition to their traders as fraudulent and gambling" (De Goede, 2005, p. 125).

\footnotetext{
${ }^{3}$ De acordo com Hochfelder (2006), bucket shops eram escritórios de corretagem não oficiais que passaram a transmitir as cotações da bolsa de valores para pessoas que antes não tinham acesso a tais informações.

${ }^{4}$ Vale lembrar que a transformação da imagem dos especuladores, de negativa a positiva, não é uma tendência única; existem movimentos no sentido contrário.
} 
Preda (2006) relata que a figura do investidor não é recente. Como brevemente esboçamos, ela existe desde o surgimento do mercado financeiro não apenas em Amsterdã, mas também em Londres e Paris, entre o final do século 17 e o início do século 18. Entretanto, nessa época, o ato de investir era claramente visto como uma atividade não econômica e que não contribuía para o enriquecimento geral da nação. Segundo Preda (2006), somente na metade do século 19 - em especial nos Estados Unidos, com a expansão das companhias de redes ferroviárias - engenheiros passaram a desenvolver guias, panfletos e manuais que foram divulgados em larga escala, contendo instruções sobre como os cidadãos poderiam "investir" suas economias e contribuir para o desenvolvimento do país.

Essa dinâmica impulsionou a aproximação entre a ciência econômica e o conhecimento popular a respeito dos investimentos financeiros. Quando alguns elementos centrais da teoria econômica começaram a ser reformulados para a elaboração de manuais, estes últimos tinham como objetivo atrair investidores populares, isto é, cidadãos comuns com capacidade de poupar e investir nas empresas que precisavam de recursos para expandir suas atividades. Para Preda (2006), a difusão desses manuais e guias foi fundamental para a transformação das percepções sobre o mercado financeiro e trouxe mudanças cognitivas com relação ao que é especulação e investimento. A ideia de que o mercado é conduzido por um grupo de especuladores foi substituída pela de que o mercado pode ser analisado por meio de leis da probabilidade. Nesse momento, teve início a fase de recodificação da crença no jogo das bolsas de valores, ou seja, a noção de investimento ressignificou a de especulação, que passou a ser percebida também como um direito social básico, próprio da natureza humana.

Ao realizar uma genealogia do mundo das finanças, De Goede (2005) explica que a especulação, antes condenada socialmente, adquire uma função moral e econômica a partir do século 20, quando tem início uma separação entre a figura do jogador e a do especulador. Esta última passa a ser sustentada pela lógica da racionalidade, atrelada à ideia de investimento que proporciona o bem comum.

Outro fato importante no percurso de legitimação do mundo financeiro ocorreu após a segunda guerra mundial, quando a Bolsa de Valores de Nova Iorque (Nyse) lançou um programa cultural para promover o mercado acionário entre os trabalhadores e a classe média. Nesse momento, a imagem da Nyse ainda estava vinculada aos efeitos da crise de 1929; entretanto, naquele período, a sociedade estava motivada pela ideia de mudança e havia grande expectativa entre os bancos e as instituições financeiras no sentido de 
promover o desenvolvimento econômico e expandir o consumo do crédito para aquecer a economia (Aitken, 2005; Calder, 1999).

De acordo com Aitken (2005), o programa promovido pela Nyse consistia em desenvolver campanhas publicitárias e atividades educacionais, assim como elaborar produtos e projetos que incluíam manuais, cursos de educação, planos de ensino para escolas, filmes, programas de televisão e de rádio. Além disso, havia programas direcionados às empresas norte-americanas, com o objetivo de incentivá-las a captar recursos financeiros através do mercado acionário. Por meio dessas iniciativas, a Nyse tentou reverter a imagem negativa do mundo financeiro, principalmente aquela associada à crise financeira de 1929. Segundo Aitken (2005, p. 348), o programa era audacioso e baseava-se na ideia de investimento em massa, que deveria ser visto como um método democrático de se obter capital que, se disseminado por toda a economia nacional, constituiria a base para a prosperidade econômica norte-americana, em contraste com a ideia de uma economia socialista, que ganhava força em outros países naquele momento. Assim, falar em democracia e popularização do mercado foi essencial para atrair novos investidores e conquistar a confiança da sociedade.

Os programas criados pela Nyse foram desenvolvidos continuamente ao longo dos anos 50 e 60 do século 20, sempre referenciando o mundo financeiro como força significante para a concepção de uma nova ordem econômica mundial (Aitken, 2005).

$\mathrm{Na}$ década de 1950, nos Estados Unidos, as empresas, as bolsas de valores e as corretoras desenvolveram uma campanha de educação chamada "Capitalismo popular". Segundo Harrington (2007), George Funston, que se tornou presidente da Nyse em 1951, alegava que comprar ações era um voto a favor da democracia, na tentativa de criar a ideia de que todos podiam se tornar "investidores patriotas". Essa expressão foi retomada quase cinquenta anos mais tarde na campanha levada a cabo através de e-mails e propaganda, lançada após os atentados de 11 de setembro de $2001 \mathrm{com}$ o intuito de incentivar os norte-americanos a comprar ações com o objetivo de estimular a economia e emitir um sinal de confiança, afrontando, assim, o ato terrorista que atingiu o centro financeiro do país (Harrington, 2007, p. 12).

Vale ressaltar a convergência entre o posicionamento do então presidente da Nyse e os programas educacionais desenvolvidos pela referida instituição. Na mesma época, no Brasil, os projetos de popularização da bolsa também estiveram fortemente vinculados à imagem do ex-presidente daquela instituição, Raymundo Magliano Filho (2001-2009), que deu início aos programas de popularização do mercado de capitais e de educação financeira, voltados para a sociedade brasileira. Magliano Filho assumiu a presidência 
da Bolsa de Valores de São Paulo em 2001 e tinha como objetivo aumentar a participação de investidores individuais (pessoa física) no mercado de capitais: "Partimos do princípio que o brasileiro não sabe o que é bolsa de valores. Então, fizemos programas de esclarecimento e educação dos investidores".

Entre os anos 50, 60 e 70 do século 20, na Europa e na América anglosaxônica, o mundo das finanças viveu momentos de euforia que constituíram a base para uma nova conexão entre o mercado financeiro e a ideia de massificação dos investimentos. Isso se deu, principalmente, devido ao crescimento de fundos de investimentos, que passaram a fazer aplicações em ações ordinárias, aquelas com direto a voto, para garantir e estimular a participação de acionistas minoritários (Erturk et al., 2005).

Segundo Erturk et al. (2005, p. 358), a quimera do "capital para todos" continuava impulsionando uma série de programas e projetos que incluíam o ideário de investment civilization, o qual previa expandir as benesses das finanças pelo mundo. Neste momento também se desenvolveram, com grande força, os intermediários financeiros do sistema capitalista. Segundo Folkman et al. (2006), estes intermediários são advogados corporativos, administradores de fundos de pensão, associados aos fundos de private equity e bancos de investimentos, os quais prestam serviços relacionados à introdução de novos pacotes gerenciais e criam ferramentas para operar, inovar e trazer segurança aos mercados de capitais.

Froud (2001) revela que, juntamente com o fortalecimento do plano de "investimento para todos" e com o avanço de novas tecnologias e de diferentes métodos de análise do mercado, surgiu uma vertente de intelectuais que fomentava a ideia de que o mercado financeiro poderia se tornar a principal atividade econômica e social do país. Atualmente, essa linha de pensamento tem forte presença no cenário norte-americano, prometendo democratizar as finanças e controlar as incertezas. De acordo com Erturk et al. (2005, p. 7), a ideia de enriquecimento rápido é "muitas vezes doente, mas nunca morre". Foi assim que tal promessa foi reafirmada na década de 2000, passando a ser sustentada por trabalhos de acadêmicos sobre as chamadas "finanças comportamentais" que ganharam repercussão mundial, como o trabalho do economista Robert Shiller (Erturk et al., 2005).

Alguns teóricos, como Poon (2009), discutem os efeitos de uma economia em que todos são convidados a participar, mostrando que a crise do subprime nos Estados Unidos (2008) foi provocada pela orquestração das tomadas de decisões e pelos conselhos de "superagentes" do mercado. O argumento

\footnotetext{
${ }^{5}$ Palavras do ex-presidente da Bovespa, Raymundo Magliano Filho citadas por Costa (2008).
} 
apresentado por Ho (2009, p. 169), que realizou uma etnografia dos bastidores de Wall Street, também corrobora a ideia de que os discursos dos experts do mercado têm o poder de moralizar e influenciar as decisões dos indivíduos.

De todo modo, a tradicional imagem de operadores "enlouquecidos" vem perdendo lentamente sua capacidade de atrair a atenção e produzir emoções. Ela tem sido substituída por representações que destacam a "racionalidade" nos mercados de capitais, ancoradas nos estudos científicos, nos métodos e softwares que dão ares de segurança e legitimam às práticas de investimento, corroborando, assim, mudanças cognitivas na sociedade. A imagem do mercado "selvagem" é, então, ressignificada através das ideias de segurança e de controle, advindas dos programas e modelos científicos legitimados pela ciência econômica, os quais aparentemente prometem controlar o caos, como veremos a seguir.

De acordo com Preda (2006), as tensões no mercado financeiro continuam a existir. Assim, as sátiras não desapareceram, e a figura do investidor ganancioso, manipulador ainda alimenta momentos de crise e compõe as ficções. Entretanto, as imagens negativas relacionadas ao investidor têm como contraponto as dos estrategistas e dos cientistas. E aqueles que não são vistos como planejadores conscientes são considerados meros especuladores egoístas, apegados à riqueza material e ao dinheiro. Em outras palavras, esse campo gera categorias normativas que caracterizam os especuladores impulsivos como figuras que devem ser excluídas dos circuitos dos mercados. Ao mesmo tempo, é importante a permanência subjetiva de tais figuras do "mal", pois qualquer evento ou escândalo que envolva o mercado terá como "bode expiatório" a imagem do investidor como especulador impulsivo e ganancioso.

Estas referências da literatura sobre os mercados ${ }^{6}$ nos oferecem um aporte heurístico para refletirmos sobre como as práticas econômicas condenadas em certas épocas são ressignificadas e passam a ganhar legitimidade social em outras. Isto é, a figura do jogador/especulador, associada à incorporação de ações e técnicas reforçadas por modelos científicos e tecnológicos, foi transformada na figura do profissional do mercado, ou melhor, do investidor consciente de suas ações. Assim, respaldada pela ciência econômica mainstream, a ideia de investimento nos mercados de capitais foi legitimada como prática "racional".

\footnotetext{
${ }_{6}$ Vale enfatizar que optei por este recorte teórico como uma tentativa de contornar a retórica existente nos trabalhos sobre cultura econômica, que passam por uma análise exaustiva das obras, em especial partindo do clássico Karl Marx. Os estudos sobre financeirização apresentados aqui, entretanto, buscam explicar a construção cultural recente dos mercados e seus principais protagonistas. Esse caminho também reduz a apresentação das informações sobre o processo de ressignificação proposto neste artigo, mudando o foco para a exposição dos promotores do mercado financeiro.
} 
A expansão do mercado financeiro recente leva economistas, jornalistas e acadêmicos de diversas áreas a discutirem a formação de uma economia que se concentra no processo de "financeirização" mundial. O avanço dessa "economia", ou seja, daquilo que alimenta a financeirização, conta primeiramente com o intermédio da mídia, que leva informações aos investidores através da forte divulgação da literatura sobre finanças para leigos; do crescimento de diversos serviços e produtos financeiros; do surgimento de analistas tais como os consultores e os planejadores financeiros (Thrift, 2008; Ho, 2009). O sucesso do mercado financeiro nesse novo contexto é reforçado por fórmulas e métodos de análise nos quais a tecnologia está fortemente presente e pode ser constantemente modulada e redefinida como vantagem para os acionistas.

É neste cenário que, no Brasil recente, inúmeras pessoas passaram a integrar o mercado financeiro, de forma indireta, aplicando recursos em investimentos de longo prazo, como os planos de previdência privada, fundos mútuos e clubes de investimento, que compram papéis das companhias listadas na bolsa (Gamez, 2006). Esse interesse pelo mercado financeiro é justificado pela mídia e por teóricos da economia com base na fase virtuosa de crescimento econômico que o mundo e, principalmente, o Brasil, experimentaram nos últimos anos (Leite, 2007; 2011). Neste cenário, foi fartamente divulgada a reconfiguração interna das instituições econômicas, com a expansão das práticas de governança corporativa (Grün, 2007) e a campanha de popularização do mercado de capitais patrocinada pela própria Bolsa de São Paulo.

Em 2002, havia 85.249 contas de pessoa física nas corretoras, bancos e distribuidoras de valores que operavam na Bovespa. ${ }^{7} \mathrm{O}$ auge da participação de investidores individuais na bolsa foi em $2010,{ }^{8}$ quando foram registradas $610.915^{9}$ contas. Em seguida, assistimos a uma flutuação na entrada e na saída destes participantes no mercado, restando 562.269 contas no ano de $2016 .^{10}$

Em 2008, a Bovespa integrou-se à Bolsa de Mercadorias \& Futuros (BM\&F), transformando-se na BM\&FBovespa. Com essa fusão, formou-se uma das mais importantes bolsas das Américas. ${ }^{11}$ Com a expansão de suas

\footnotetext{
${ }^{7}$ Número de investidores pessoa física na Bolsa recua em setembro. InfoMoney, São Paulo, 6 out. $2011<$ http://economia.uol.com.br/ultimas-noticias/infomoney/2011/10/06/numero-deinvestidores-pessoa-fisica-na-bolsa-recua-em-setembro.jhtm> (8 out. 2011).

${ }^{8}$ A explicação recorrente nos principais veículos de informação sobre o aumento do número de pessoas físicas na Bolsa de Valores faz referência aos programas de popularização elaborados pela própria Bovespa desde 2002 (Leite, 2011).

9 Dados coletados no site da BM\&FBovespa: <www.bmfbovespa.com.br/pt-br/mercados/ Historico-Pessoas-Fisicas.xls> (jun. 2016).

${ }^{10} \mathrm{Ibidem}$. Os dados mostram os números até junho de 2016.

${ }^{11}<$ ri.bmfbovespa.com.br/site/portal_investidores/pt/a_bovespa/perfil/perfil.aspx> (jan. 2010).
} 
atividades, a meta da BM\&FBovespa, em especial até 2015, era atrair cinco milhões de investidores pessoa física para o mercado acionário brasileiro. Para isso, foi lançado, em 2010, o programa “Quer ser sócio?”, uma campanha publicitária que tinha o jogador Pelé como protagonista. O filme que dava impulso ao projeto relatava a história de vida do jogador de futebol, com seus "altos e baixos", traduzidos em um gráfico similar aos que ilustram o desempenho de uma empresa ao longo do tempo, com o objetivo de demonstrar que aqueles que compraram ações da "Pelé S/A" foram recompensados com ganhos financeiros a longo prazo. ${ }^{12}$

A recente expansão do mercado financeiro é atribuída a diversos fatores, como o bom desempenho da economia e a estabilidade política brasileira que reinou ao longo da primeira década do século $20 .{ }^{13}$ Entretanto, a não conquista da meta de investidores a ser atingida pelo programa até 2015 foi justificado pelos agentes do mercado financeiro pelo fato das instituições políticas e econômicas brasileiras terem deixado de sinalizar a confiança necessária para que o mercado continuasse o seu rumo de crescimento.

De certa forma, o cenário de otimismo que vigorou naquele período promoveu o crescimento do número de agentes do mercado que expandiram o seu campo de atuação. Um exemplo disso são as corretoras de valores mobiliários que antes tinham papel ofuscado e que ganharam protagonismo na busca e na formação do investidor individual através da ampliação da oferta de cursos sobre educação financeira. Mesmo em momentos de crise, o discurso destes agentes reforçava que os brasileiros "perdem" no mercado e têm medo das crises porque não são educados financeiramente para participar de sua volatilidade.

Neste momento, vale a pena voltar ao exercício sociológico para refletirmos sobre a narrativa do sucesso do mercado financeiro no Brasil. Ao explorar as recentes transformações do espaço econômico brasileiro, Grün (2009, p. 3) revela que o campo financeiro apresenta uma "pressuposição espontânea de que o seu principal produto é simplesmente a produção de riqueza material ou a sua transferência de uns para outros". O autor alerta que a compreensão sociológica desse espaço em construção é fundamental para não cairmos na armadilha que a própria produção de sentidos do campo financeiro produz (Bourdieu, 2003; Grün, 2009).

\footnotetext{
$12<$ quersersocio.com.br/\#/home $>$ (set. 2010).

${ }^{13}$ Ver detalhes em: <bmfbovespa.com.br/InstSites/RevistaBovespa/86/Popularizacao.shtml> (set. 2010).
} 
A criação, pela Bovespa, dos níveis de governança corporativa, via a concepção do "Novo Mercado", em 2002, inaugurou uma nova fase do mercado de capitais no Brasil, como veremos a seguir. A proposta do "Novo Mercado" se apoiava em quatro pilares: transparência, equidade, prestação de contas e responsabilidade social - princípios que visam a homogeneizar o mercado e reduzir suas incertezas. ${ }^{14}$ No que se refere em especial à questão da transparência, que ganha ênfase com a introdução das boas práticas de governança corporativa no Brasil, a bolsa procurou distanciar-se da ideia de cassino e de jogos de azar, o que fica bem evidente, por exemplo, no trecho retirado do jornal Valor Econômico (2006), um dos principais jornais de economia do Brasil.

Há um falso pressuposto filosófico no mercado brasileiro de que investir em ações é arriscado. Ações são parcelas do capital de companhias abertas. Não são fichas para se jogar em um cassino. Ao deter para si ações de empresas listadas em bolsa, o investidor torna-se acionista de uma empresa submetida às regras de governança corporativa [grifo meu]. ${ }^{15}$

Grün (2003) revela, por outro lado, que, no período de redemocratização política do país, o mercado mobiliário brasileiro passa a se amparar ideologicamente na crítica ao modelo administrativo burocrático que predominou no período dos governos militares, consolidando a importação dos Estados Unidos da ideia de "governança corporativa”. Segundo, Grün é, a partir deste momento, que se inicia o processo de subordinação das esferas política, econômica e social da sociedade brasileira à financeirização. Desse modo, as propostas de governança corporativa ganharam força efetivamente durante o governo Fernando Henrique Cardoso, no contexto de privatização das empresas públicas (Grün, 2003; 2004), tendo em vista que, naquele momento, falar de transparência era essencial para impulsionar a venda das empresas estatais e atrair investidores.

Mais adiante, durante a campanha eleitoral de 2002, o candidato Luiz Inácio Lula da Silva buscou conquistar o mercado financeiro demonstrando confiança e atraindo novos aliados. Nessa ocasião, as propostas de governança corporativa apareceram na agenda do governo Lula, facilitando a criação de um ambiente institucional favorável ao mercado financeiro, já que, as boas

\footnotetext{
${ }^{14}$ De: <www.bmfbovespa.com.br/pt-br/a-bmfbovespa/download/Folder_NovoMercado.pdf> (set. 2010).

${ }^{15} \mathrm{O}$ avanço do mercado de capitais no Brasil. Valor Econômico, São Paulo, 13 abr. 2006.
} 
práticas de governança corporativa buscavam gerar confiança e transparência, embasando o discurso apropriado para um governo que, por sua trajetória, gerava insegurança para o mercado (Grün, 2003).

De acordo com Jardim (2009), durante a primeira década do século 20, o Brasil passou por um processo de moralização e domesticação do capitalismo. A autora salienta que o governo Lula implementou políticas de inclusão social por meio do mercado. Isto posto, é possível afirmar que certos projetos sociais implementados por esse governo, como o microcrédito e o banco popular, entre outros, que dependiam da dinâmica do mercado, permitiram a criação de uma retórica que tentava negar a ideia de que o mercado funciona exclusivamente voltado para a busca pelo lucro, redefinindo, assim, o conceito de mercado financeiro (Jardim, 2009).

Alguns estudos demonstram como eventos semelhantes ocorreram nos Estados Unidos na década de 50, tendo como objetivo atrair trabalhadores e demais cidadãos para o mercado de capitais via programas de educação financeira, como forma de democratizar a economia capitalista e evitar a possível ascensão de uma economia socialista (Aitken, 2005). É interessante notar que, durante a campanha presencial do então candidato Lula, em 2001, estratégias semelhantes foram tomadas pelo mercado financeiro brasileiro, na tentativa de "boicotar" uma eventual reviravolta econômica advinda da ascensão de um governo que teoricamente era de esquerda.

Em outro trabalho (Leite, 2007), tentei demonstrar que o discurso que vem com o rótulo de "educação financeira" promovido pela bolsa de São Paulo adaptou conceitos como democracia, visibilidade e livre acesso para legitimar o atual predomínio da esfera financeira e atrair empresas e indivíduos, e reforçar a visão de que o aumento do investimento popular no mercado acionário é essencial para democratizar a economia. A educação financeira promovida por tais instituições não se orienta apenas pelo incentivo aos investimentos na bolsa de valores brasileira, mas tem também como objetivo organizar a vida econômica dos indivíduos (Leite, 2011). A temática da educação financeira chega a diversos setores da sociedade através de consultores financeiros cada vez mais presentes em programas populares de tevê; da expansão do mercado editorial de autoajuda financeira, mas também da produção de catálogos de empresas com penetração popular (por exemplo, a empresa de cosméticos Avon); da expansão do setor de crédito e avanço das políticas de microcrédito; do crescimento dos financiamentos para habitação estimulados pelo governo federal; da criação de novos serviços oferecidos pelos bancos; e até mesmo através das palavras de pastores das igrejas neopentecostais incentivando a poupança e os investimentos (Leite, 2011). 
Os próprios agentes do mercado financeiro, em especial os promotores dos programas de educação financeira da Bolsa de São Paulo e os consultores que ganharam espaço recentemente como gurus financeiros (Leite, 2011), são os principais agentes dessa "ressignificação". De certa forma, esses agentes "demonizam" os mercados financeiros para poder, em seguida, revelar como, hoje, são mecanismos para novas possibilidades de investimento. Assim, os especuladores e gananciosos são vistos de maneira pejorativa, enquanto os investidores assumem a conotação de "racionais" e responsáveis, como exemplifica o trecho:

[...] $\mathrm{O}$ investidor inteligente segue um roteiro antes de investir, atuando numa base quase que $100 \%$ racional, já o ganancioso se deixa levar pelo calor do momento, dando ordens de compra e venda no calor da emoção", explica Rafael Paschoarelli, professor de Finanças e autor do livro Como ganhar dinheiro no mercado financeiro. ${ }^{16}$

Em O financiamento do sonho norte-americano, Calder (1999) descreve a expansão do consumo de crédito nos Estados Unidos, ocorrida nos anos de 1920, e afirma que, até então, pairava uma moral negativa sobre o endividamento, isto é, sobre a utilização do crédito para suprir desejos e necessidades consideradas supérfluas. A dívida, nesse caso, estava associada à fraqueza de caráter do indivíduo, que seria incapaz de controlar seus impulsos para o prazer. Da mesma forma, prevalecia a ideia de que a disposição para o trabalho se enfraqueceria com a expansão do mercado de crédito. De modo geral, as ações de educação financeira visavam a remover o empecilho moral que condenava o crédito para a compra de produtos "fúteis", fator essencial para impulsionar o mercado consumidor e o crescimento do setor industrial.

No Brasil dos anos 2000, entretanto, a maioria dos consultores financeiros e veículos da mídia utilizam a educação financeira para condenar o hábito de gastar sem necessidade, e apontar a oferta de produtos ligados ao crédito como os principais vilões a serem combatidos para a conquista da independência financeira. Assim, estatísticas sobre o aumento do número de endividados são massivamente divulgadas, e as consequências negativas do endividamento tornam-se argumentos para salientar a necessidade de educação financeira e de planejamento orçamentário. Tais multiplicadores das finanças acabam disseminando intensamente a prática da poupança e do investimento

\footnotetext{
${ }^{16}$ Informações retiradas de: <http://www.revistainvestmais.com.br/comofunciona/210-Qual+e+o + seu+perfil+de+investidor+Comportamento.html > (jan. 2016).
} 
em ações por meio de programas e materiais didáticos que fazem referência à necessidade de educação financeira.

É possível notar, portanto, que, por meio de "novas convenções sociais" (Douglas e Ney, 1998), os indivíduos são chamados pelos consultores para, ao menos, refletirem sobre a ética e a moral no que tange as suas práticas de investimento. Assim, o indivíduo esbanjador e consumista passa a ser vilão do novo estilo de vida projetado pelos fornecedores dessas ideias, ao passo que "investir" no mercado de capitais, como vimos, passa a ser uma ação socialmente legítima.

Um novo ideário que procura transformar o indivíduo em investidor é formado, em contraposição à figura do consumista e devedor. Hoje em dia, a imagem do indivíduo bem-sucedido é composta por aquele sujeito que poupa e investe, ou seja, aquele que usa o dinheiro com "racionalidade" para atingir a sua independência financeira. Neste sentido, a temática da educação financeira como vem sendo propalada pelos consultores, funciona como um filtro que, por meio de programas, métodos, livros, eventos, palestras, revistas, jornais e telejornais, busca ressignificar as práticas econômicas (Leite, 2011).

A educação financeira no Brasil tornou-se, pois, uma espécie de trunfo social compartilhado por diversos agentes e grupos promotores da educação financeira no país. Pode-se dizer, então, que se observa a formação de um espaço social envolto na propagação da educação financeira, que se constitui como cenário perfeito para a promoção do mundo das finanças e da imagem positiva do investidor (racional), afinal, qualquer pauta em relação aos aspectos econômicos, como crédito, endividamento, poupança e investimento, é motivo para que consultores e demais profissionais do campo das finanças defendam a necessidade de educação financeira. Assim, o mundo das finanças, envolto pela temática da educação financeira, se espraia para diversos setores da população brasileira.

As estratégias de educação financeira foram levadas a cabo tanto pelo governo federal quanto por iniciativas privadas. Os "vilões" que compõem tal cenário - como os endividados ou mesmo os especuladores gananciosos, que devem ser combatidos para a conquista da independência financeira - na verdade são cúmplices subjetivos que dão dinâmica ao campo do mercado financeiro (Bourdieu, 2003) e alimentam o avanço das finanças, abrindo espaços para o desenvolvimento de um mercado de conselhos econômicos que, por sua vez, garante a legitimidade da imagem positiva do investidor e dos programas de educação financeira no país. Assim, legitima-se a especulação, revestida de investimento, para o bem da nação. 


\section{Referências}

AITKEN, Rob. 'A direct personal stake': cultural economy, mass investment and the New York stock exchange. Review of International Political Economy, v. 12, n. 2, p. 334-363, $2005<10.1080 / 09692290500105771>$.

BOURDIEU, Pierre. Las estructuras sociales de la economía. Barcelona: Editorial Anangrama, 2003.

CALDER, Lendol. Financing the American dream: a cultural history of consumer credit. Princeton: Princeton University Press, 1999.

CALLON, Michel. Why virtualism paves the way to political impotence: a reply to Daniel Miller's critique of the laws of the markets. Economic Sociology: European Electronic Newsletter, v. 6, n. 2, p. 3-20, $2005<$ http://econsoc.mpifg.de/archive/ esfeb05.pdf> (29 nov. 2016).

CARDOSO, José Luis. Confusion de confusiones: ethics and options on seventeenthcentury stock exchange markets. Financial History Review, v. 9, n. 2, p. 109-123, 2002 $<10.1017 /$ S0968565002000100>.

COSTA, J. E. Bate papo com o presidente da Bovespa. Você $S / A$, São Paulo, 9 jul. 2008.

DE GOEDE, Marieke. Virtue, fortune and faith: a genealogy of finance. Minneapolis: University of Minnesota Press, 2005.

DOUGLAS, Mary; NEY, Steven. The strong presence of homo economicus. In: Mary Douglas; Steven Ney. Missing persons: a critique of the social science. New York: Russell Sage Foundation, 1998. p. 22-45.

ERTURK, Ismail; FROUD, Julie; JOHAL, Sukhdev; LEAVER, Adam; WILLIAMS, Karel. The democratisation of finance? Promises, outcomes and conditions. Cresc Working Paper Series, n. 9, 2005.

FOLKMAN, Peter; FROUD, Julie; JOHAL, Sukhdev; WILLIAMS, Karel. Working for themselves? Capital market intermediaries and present day capitalism. Cresc Working Paper Series, n. 25, 2006.

FROUD, Julie; HASLAM, Colin; JOHAL, Sukhdev; WILliAMS, Karel. Financialisation and the coupon pool. Gestão \& Produção, v. 8, n. 3, p. 271-288, 2001 $<10.1590 /$ S0104-530X2001000300005>.

GAMEZ, Molton. Os investidores estão voltando. Revista Bovespa, jan.-mar. 2006 <www.bovespa.com.br/InstSites/RevistaBovespa/97/Capa.shtml> (23 nov. 2008).

GRÜN, Roberto. Atores e ações na construção da governança corporativa brasileira. Revista Brasileira de Ciências Sociais, v. 18, n. 52, p. 139-161, $2003<10.1590 /$ S010269092003000200008>.

GRÜN, Roberto. A evolução recente do espaço financeiro no Brasil e alguns reflexos na cena política. Dados, v. 47, n. 1, p. 5-47, $2004<10.1590 /$ S0011-52582004000100001>.

GRÜN, Roberto. Decifra-me ou te devoro! As finanças e a sociedade brasileira. Mana, v. 13 , n. 2 , p. $381-410,2007<10.1590 /$ S0104-93132007000200004>. 
GRÜN, Roberto. A crise, a guerra cultural e as surpreendentes transformações do espaço econômico brasileiro em 2009. Colóquio internacional: A internacionalização das ciências sociais francesas e a cooperação científica com o Brasil. Campinas: Unicamp, 2009.

HARRINGTON, Brooke. Capital and community: findings from the American investment craze of the 1990s. Economic Sociology: European Eletronic Newsletter, v. 8, n. 3, p. 19-25, 2007.

HO, Karen. Liquidated: an ethnography of Wall Street. Durham: Duke University Press, 2009.

HOCHFELDER, David. Where the common people could speculate: the ticker, bucket shops, and the origins of popular participation in financial markets, 1880-1920. Journal of American History, v. 93, n. 2, p. 335-358, 2006.

JARDIM, Maria Aparecida Chaves. Entre a solidariedade e o risco: sindicatos e fundos de pensão em tempos de governo Lula. São Paulo: Annablume, 2009.

KREMP, Pierre. Stock-market participation and their evolution from 1995 to 2007. Working paper, $2008<$ faculty.chicagobooth.edu/workshops/orgs-markets/archive/ pdf/Kremp.pdf>.

LEITE, Elaine Silveira. Governança corporativa e mídia: a construção do mercado financeiro no Brasil. São Carlos, 2007. Dissertação de mestrado, Programa de Pós-Graduação em Engenharia de Produção, Universidade Federal de São Carlos.

LEITE, Elaine Silveira. Reconversão de habitus: o advento do ideário de investimento no Brasil. São Carlos, 2011. Tese de doutorado, Programa de Pós-Graduação em Sociologia, Universidade Federal de São Carlos <https://repositorio.ufscar.br/ bitstream/handle/ufscar/6678/4111.pdf> (29 nov. 2016).

MACKENZIE, Donald; MILLO, Yuval. Constructing a market, performing theory: the historical sociology of a financial derivatives exchange. American Journal of Sociology, v. 109, n. 1, p. 107-145, $2003<10.1086 / 374404>$.

MORAES, M. No século XVII, as tulipas deixaram Amsterdã à beira da bancarrota. Folha de São Paulo, São Paulo, 21 set. 2008.

MÜLLER, Lucia Helena Alves. Mercado exemplar: um estudo antropológico sobre a Bolsa de Valores. Brasília, 1997. Tese de doutorado, Programa de Pós-Graduação em Antropologia Social, Universidade de Brasília.

POON, Martha. From New Deal institutions to capital markets: commercial consumer risk scores and the making of subprime mortgage finance. Accounting, Organizations and Society, v. 34, n. 5, p. 654-674, $2009<10.1016 /$ j.aos.2009.02.003>.

PREDA, Alex. On ticks and tapes: financial knowledge, communicative practices, and information technologies on $19^{\text {th }}$ century financial markets. In: Columbia workshop on social studies of finance. New York, 2002.

PREDA, Alex. The investor as a cultural figure of global capitalism. In: K. K. Cetina; A. Preda (orgs.). The sociology of financial markets. Nova Iorque: Oxford University Press, 2006. 
THRIFT, Nigel. The new economy and a new market culture. In: Ismail Erturk; Julis Froud; Sukhdev Johal; Adam Leaver; Karel Williams (orgs.). Financialization at work: key texts and commentary. Londres: Routledge, 2008.

ZALOOM, Caitlin. Out of the pits: traders and technology from Chicago to London. Londres: University of London Press, 2006.

Recebido em: 30 jun. 2016

Aceito em: 15 dez. 2016

Autora correspondente:

Elaine da Silveira Leite

Rua Coronel Alberto Rosa 154, 3 o andar - Centro

96010-770 Pelotas, RS, Brasil 